\title{
Fast-responsive Temperature-sensitive Hydrogels
}

\author{
Xiaohui Wang, Qingqing Dai, Haoquan Zhong, Xinxin Liu, and Junli Ren* \\ Temperature fast-responsive and magnetic poly $(N$-isopropylacrylamide- \\ co-acrylamide) (CMX-MNP-PNIPAm/ $\mathrm{Fe}_{3} \mathrm{O}_{4}$ ) hydrogels were developed \\ using carboxymethyl xylan (CMX) as a pore-forming agent and a $\mathrm{NaCl}$ \\ solution as the reaction medium, followed by fabricating $\mathrm{Fe}_{3} \mathrm{O}_{4}$ \\ nanoparticles in situ within the hydrogel matrix. It was found that $\mathrm{NaCl}$ \\ played a role in the phase separation and was used as the electrolyte to \\ shield CMX molecular chains. The obtained hydrogels exhibited a fast, \\ temperature-responsive behavior, and the water retention was less than \\ $15 \%$ for 1 min under $60^{\circ} \mathrm{C}$. The prepared hydrogels showed enhanced \\ mechanical properties and magnetic properties due to the presence of \\ $\mathrm{Fe}_{3} \mathrm{O}_{4}$ particles. The lower critical solution temperature of the hydrogels \\ was in the range of 35 to $39^{\circ} \mathrm{C}$, which was acquired through adjusting the \\ amount of hydrophilic monomer (AM). The magnetic and thermosensitive \\ hydrogel had the attractive photothermal conversion ability and could be \\ heated to $40^{\circ} \mathrm{C}$ within $2 \mathrm{~min}$, and to $69^{\circ} \mathrm{C}$ within 7 min under near infrared \\ irradiation.
}

Keywords: Temperature fast-responsive hydrogels; Carboxymethyl xylan; Pore-forming agent; Magnetic property; Photothermal conversion

Contact information: State Key Laboratory of Pulp and Paper Engineering, South China University of Technology, Guangzhou, 510640, Guangdong, China; *Corresponding author: renjunli@scut.edu.cn

\section{INTRODUCTION}

Recently, intelligent hydrogels have attracted considerable attention because of their multiple environmental response behaviors, including sensitivity to temperature, $\mathrm{pH}$, salt, and biomolecules (Peng et al. 2011b; Dai et al. 2016). These attributes make them have great potential in the biomedical field as targeted drug release agents, superabsorbents, and biosensors. Temperature-sensitive hydrogels are intelligent materials that can respond to temperature according to the reversible change in volume (swelling/ deswelling) via absorbing or releasing water or other liquids (Higgins et al. 2016). Poly(Nisopropylacrylamide) (PNIPAm) hydrogel, as a typical temperature-sensitive hydrogel, has the characteristics of thermal shrinkage (showing a lower critical solution temperature, LCST) due to hydrophilic amino groups and hydrophobic isopropyl groups within the hydrogel (Ashraf et al. 2016). Below the LCST, PNIPAm hydrogels are swollen and hydrophilic, while as the temperature exceeds the LCST, they exhibit a collapse and dehydration because the hydrophile/hydrophobicity balance in the hydrogel network structure is destroyed (Shekhar et al. 2016).

However, traditional PNIPAm hydrogels have a poor response rate to temperature change because the dense surface of hydrogels hinders the discharge of internal water molecules in the deswelling process, which limits their application in many fields (Shibayama and Nagai 1999). The response rate of temperature is an important factor in the evaluation of temperature-sensitive hydrogels. A great deal of effort has been devoted to improving the temperature response rate of PNIPAm hydrogels, and some effective 
methods have been developed, including phase-separation and pore-forming agent methods (Zhang and Zhuo 2000; Cheng et al. 2003). For example, the PNIPAm hydrogels in some inorganic salts or saccharides solution could result in a phase-separation and then enhance the rate of shrinkage. Aqueous sucrose solutions were used to prepare temperature-sensitive PNIPAm hydrogels with faster response rates and higher swelling ratios. The response rate of hydrogels prepared in the $0.15 \mathrm{M}$ sucrose solution was obviously faster than that of conventional hydrogels prepared in pure water (Watsons). The former lost at least $80 \%$ water in $10 \mathrm{~min}$, while the latter lost only approximately $15 \%$ water within $10 \mathrm{~min}$ and took $24 \mathrm{~h}$ to reach the equilibrium. This improved property was ascribed to the porous structure of hydrogels, which was caused by the phase separation in the sucrose solution (Zhang et al. 2003a). The fast response PNIPAm hydrogels were prepared in the aqueous glucose solution. The hydrogels prepared in the $1.0 \mathrm{M}$ glucose solution released $95 \%$ water in $5 \mathrm{~min}$, whereas the conventional hydrogels prepared without glucose solution lost approximately $40 \%$ water in $20 \mathrm{~min}$. These properties were due to the glucose solution impact, which caused the phase separation and formed a porous structure during hydrogels preparation (Cheng et al. 2003). The aqueous $\mathrm{NaCl}$ solution was applied as the reaction medium to synthesize temperature-sensitive PNIPAm hydrogels with fast, response behavior. Hydrogels prepared in the $1.0 \mathrm{M} \mathrm{NaCl}$ solution released at least $95 \%$ water in $5 \mathrm{~min}$, while the gels prepared in pure water released approximately $50 \%$ water in $120 \mathrm{~min}$. The salt influence led to the phase separation and resulted in heterogeneous macroporous structures during the polymerizations (Cheng et al. 2003).

A pore-forming agent is another effective method to improve the temperaturesensitive rate of PNIPAm hydrogels. Fast-responsive PNIPAm hydrogels were prepared with polyethylene glycol (PEG) as the pore-forming agent. The response rate of hydrogels prepared in the presence of PEG was significantly faster than that of hydrogels prepared in the absence of PEG. The former released approximately $95 \%$ water in 3 min and the later lost only $40 \%$ water in $68 \mathrm{~min}$ because PEG acted as the pore-forming agent, which resulted in producing a large amount of macroporous structures during the polymerizations and macroporous hydrogels could absorb more water and exhibit a fast response rate (Zhang and Zhuo 2000). A fast-responsive PNIPAm hydrogel with macroporous structure was fabricated using carboxymethyl cellulose (CMC) as the pore-forming agent (Wu et al. 1992). Hydrogels prepared in the presence of CMC reached to the swelling equilibrium (no longer absorb water) in only a few minutes, which was at least 10 -fold faster than that of hydrogels prepared in the absence of CMC. The faster response was attributed to the existence of CMC, which resulted in many open pores by occupying extra volume during the polymerization of hydrogels. After the polymerization, $\mathrm{CMC}$ was washed out from the hydrogels, and macroporous structure was formed within the hydrogels.

Xylan is an abundant, nontoxic, biodegradable, widely available, and natural polysaccharide (Ebringerová and Heinze 2000) that can be modified to form multifunctional polymers by different methods, such as oxidation, carboxymethylation, esterification, and so on. Recently, a series of hemicelluloses-based intelligent hydrogels were prepared by introducing functional xylan. These synthesized hydrogels exhibited controllable swelling abilities, temperature sensitivity, $\mathrm{pH}$ sensitivity, and magnetic properties (Peng et al. 2012; Gao et al. 2014, 2015), which make them promising materials for a variety of applications. However, there are few studies on xylose or xylan derivative as the pore-forming agent to prepare intelligent hydrogels.

Carboxymethylation enables xylan to have anionic properties by introducing more $-\mathrm{COO}^{-}$groups on its main chain. In an aqueous salt solution, the repulsion between 
carboxymethyl xylan (CMX) molecular chains became weaker and promoted the curl of CMX molecular chains, which was beneficial to producing a large amount of porous structures in the preparation of hydrogels. In this work, carboxymethyl xylan was prepared, and for the first time used as the pore-forming agent to prepare temperature fast-responsive magnetic hydrogels (CMX-MNP-PNIPAm/ $\left./ \mathrm{Fe}_{3} \mathrm{O}_{4}\right)$ in the $\mathrm{NaCl}$ solutions. The impact of $\mathrm{CMX}$ as the pore-forming agent was studied on the hydrogel's properties as well as the $\mathrm{NaCl}$ solution. The characteristics of the prepared hydrogels were determined via scanning electron microscopy (SEM), carbon-13 nuclear magnetic resonance $\left({ }^{13} \mathrm{C}-\mathrm{NMR}\right)$ spectrometry, thermogravimetric analysis (TGA), vibrating sample magnetometry (VSM), differential scanning calorimetry (DSC), X-ray diffraction (XRD), and Raman spectra. The photothermal conversion properties of the obtained hydrogels were also investigated.

\section{EXPERIMENTAL}

\section{Materials}

Beech wood xylan ( $M_{\mathrm{w}}$ of 100,000 to $130,000 \mathrm{~g} / \mathrm{mol}$ ) was obtained from Sigma Aldrich (Karlsruhe, Germany). Acrylamide (AM, 98\%), NIPAm (98\%), chloroacetic acid (99\%), ammonium persulfate (99\%), tetramethylethylenediamine (TEMED, 99\%), N, $N^{\prime}-$ methylenebisacrylamide (MBA, 98\%), $\mathrm{FeSO}_{4} \cdot 7 \mathrm{H}_{2} \mathrm{O}, \mathrm{FeCl}_{3} \bullet 6 \mathrm{H}_{2} \mathrm{O}, \mathrm{NaOH}$, and $\mathrm{NaCl}$ were supplied by Aladdin Reagent Co., Ltd. (Shanghai, China). Glacial acetic acid (99\%), ammonium hydroxide $\left(\mathrm{NH}_{3} \cdot \mathrm{H}_{2} \mathrm{O}, 25 \%\right.$ to $\left.28 \%\right)$, ethanol, and $\mathrm{H}_{2} \mathrm{O}_{2}$ were received from Guangzhou Chemical Reagent Company (Guangzhou, China). All the reagents were used without further purification.

\section{Methods}

Preparation of carboxymethyl xylan

The type of preparation procedure of CMX was conducted according to the authors' previous work (Ren et al. 2008). A total of $6.6 \mathrm{~g}$ of xylan was dissolved in $25 \mathrm{~mL}$ of distilled water with vigorous magnetic stirring at $80^{\circ} \mathrm{C}$ for $70 \mathrm{~min}$. After the solutions were cooled to $30{ }^{\circ} \mathrm{C}, 2 \mathrm{~mL}$ of the $\mathrm{NaOH}$ solution $(12.5 \mathrm{~mol} / \mathrm{L})$ was added and stirred for 20 $\mathrm{min}$. The $11-\mathrm{mL}$ sodium chloroacetate solution $(0.1 \mathrm{~mol} / \mathrm{L})$ and the $2-\mathrm{mL} \mathrm{NaOH}$ solution $(12.5 \mathrm{~mol} / \mathrm{L})$ were added into the above solution, and the reaction mixture solution was irradiated at $65^{\circ} \mathrm{C}$ for 20 min with a $300 \mathrm{~W}$ microwave (VIP 200; Whirlpool, Michigan, America). After reaction, the mixture was first cooled down, then neutralized with diluted acetic acid, and dialyzed in dialysis bag $\left(M_{\mathrm{w}}\right.$ of 3000$)$ for a week. The purified carboxymethyl xylan was freeze-dried and preserved. The degree of substitution (DS) of the CMX was 0.85 , which was measured by the acidometric titration method.

\section{Preparation of magnetic temperature fast-responsive hydrogels}

A total of $2 \mathrm{~g}$ of NIPAm were dissolved in different concentration $\mathrm{NaCl}$ solutions, and different amounts of CMX, AM, and MBA were added into the mixtures in a water bath at $10{ }^{\circ} \mathrm{C}$ for magnetic stirring. After bubbling $\mathrm{N}_{2}$ for $20 \mathrm{~min}$, a certain amount of ammonium persulfate was first added in the mixtures as the initiator, and after $10 \mathrm{~min}$ TEMED was added to end the reaction. Subsequently, the mixture was poured into a glass mould at $25^{\circ} \mathrm{C}$ for $6 \mathrm{~h}$. After reaction, the mould was removed and the obtained hydrogels were washed with distilled water. Subsequently, the prepared hydrogels were cut into cubes and immersed in the mixture solution $\left(40 \mathrm{~mL}\right.$ ) containing $2 \mathrm{mmol}$ of $\mathrm{FeCl}_{3} \cdot 6 \mathrm{H}_{2} \mathrm{O}$ and 1 
mmol of $\mathrm{FeSO}_{4} \cdot 7 \mathrm{H}_{2} \mathrm{O}$ for $6 \mathrm{~h}$ under a nitrogen atmosphere. Then, hydrogels loaded with iron ions were transformed into $30 \mathrm{~mL}$ of $\mathrm{NH}_{3} \cdot \mathrm{H}_{2} \mathrm{O}$ for 30 min under a nitrogen atmosphere. Finally, black hydrogels were obtained and washed with distilled water to remove excess ions and impurity. The detailed synthesis conditions are shown in Table 1.

Table 1. Preparation Conditions of the CMX-MNP-PNIPAm Hydrogels

\begin{tabular}{|c|c|c|c|c|c|c|}
\hline Entries & NIPAm $(\mathrm{g})$ & $\mathrm{CMX}(\mathrm{g})$ & $\mathrm{MBA}(\mathrm{g})$ & $\mathrm{AM}(\mathrm{g})$ & $\mathrm{NaCl}(\mathrm{mol} / \mathrm{L})$ & $\mathrm{H}_{2} \mathrm{O}(\mathrm{mL})$ \\
\hline $\mathrm{MBA}_{0.05}$ & 2 & 0.12 & 0.05 & 0.1 & 0.4 & 24 \\
\hline $\mathrm{MBA}_{0.10}$ & 2 & 0.12 & 0.1 & 0.1 & 0.4 & 24 \\
\hline $\mathrm{MBA}_{0.15}$ & 2 & 0.12 & 0.15 & 0.1 & 0.4 & 24 \\
\hline $\mathrm{MBA}_{0.20}$ & 2 & 0.12 & 0.2 & 0.1 & 0.4 & 24 \\
\hline $\mathrm{AM}_{0.05}$ & 2 & 0.12 & 0.1 & 0.05 & 0.4 & 24 \\
\hline $\mathrm{AM}_{0.10}$ & 2 & 0.12 & 0.1 & 0.1 & 0.4 & 24 \\
\hline $\mathrm{AM}_{0.20}$ & 2 & 0.12 & 0.1 & 0.2 & 0.4 & 24 \\
\hline $\mathrm{AM}_{0.40}$ & 2 & 0.12 & 0.1 & 0.4 & 0.4 & 24 \\
\hline $\mathrm{NaCl}_{0}$ & 2 & 0.12 & 0.1 & 0.05 & -- & 24 \\
\hline $\mathrm{NaCl}_{0.2}$ & 2 & 0.12 & 0.1 & 0.05 & 0.2 & 24 \\
\hline $\mathrm{NaCl}_{0.4}$ & 2 & 0.12 & 0.1 & 0.05 & 0.4 & 24 \\
\hline $\mathrm{NaCl}_{0.6}$ & 2 & 0.12 & 0.1 & 0.05 & 0.6 & 24 \\
\hline $\mathrm{CMX} / \mathrm{NaCl}_{0}$ & 2 & -- & 0.1 & 0.05 & -- & 24 \\
\hline $\mathrm{CMX} / \mathrm{NaCl}_{0.2}$ & 2 & -- & 0.1 & 0.05 & 0.2 & 24 \\
\hline $\mathrm{CMX} / \mathrm{NaCl}_{0.4}$ & 2 & -- & 0.1 & 0.05 & 0.4 & 24 \\
\hline $\mathrm{CMX}_{0} / \mathrm{NaCl}_{0.6}$ & 2 & -- & 0.1 & 0.05 & 0.6 & 24 \\
\hline $\mathrm{CMX} / \mathrm{MBA} \mathrm{AM}_{\mathrm{NaCl}}$ & 2 & 0.12 & 0.2 & 0.05 & 0.6 & 24 \\
\hline
\end{tabular}

Characterization of the hydrogels

Surface morphology of hydrogels and images of $\mathrm{Fe}_{3} \mathrm{O}_{4}$ nanoparticles in hydrogels were recorded using SEM (Quanta 200; FEI Company, Hillsboro, USA) and field emission (FE)-SEM (JSM-7000F; JEOL Co., Ltd., Beijing, China) with an accelerating voltage of $10 \mathrm{kV}$ and $20 \mathrm{kV}$, respectively. The ${ }^{13} \mathrm{C}-\mathrm{NMR}$ of xylan, CMX, and hydrogels were analyzed using a Bruker AV-III $400 \mathrm{M}$ (Bruker, Karlsruhe, Germany). The solvent and the internal standard were $\mathrm{D}_{2} \mathrm{O}$ and trimethylsilane, respectively. The XRD patterns of hydrogels were tested on a Bruker diffractometer with $\mathrm{Cu} \mathrm{K} \alpha$ radiation (Bruker, Karlsruhe, Germany) in the range of $20^{\circ}$ to $80^{\circ}$. The magnetic hydrogels were measured using VSM (LakeShore-7307; Lakeshore Company, Columbus, OH, USA) at room temperature. The Raman spectra (HORIBA HR 800; HORIBA H.J.Y Company, Paris, France) of hydrogels were recorded at $632.8 \mathrm{~nm}$ radiation from an argon ion laser with an output power of 20 $\mathrm{mW}$ and a typical acquisition time of $10 \mathrm{~s}$. The TGA experiments of hydrogels were performed using a TGA Q500 instrument (New Castle, DE, USA) under a nitrogen flow of $20 \mathrm{~mL} / \mathrm{min}$ from 50 to $600{ }^{\circ} \mathrm{C}$ at a heating rate of $10{ }^{\circ} \mathrm{C} / \mathrm{min}$. The DSC experiments for LCST determination were from $-10{ }^{\circ} \mathrm{C}$ to $60^{\circ} \mathrm{C}$ with a heating rate of $2{ }^{\circ} \mathrm{C} / \mathrm{min}$ on a DSCQ2000 apparatus (TA Instruments, Newcastle, DE, USA) under a nitrogen flow of 25 $\mathrm{mL} / \mathrm{min}$. The compressive strength of hydrogels was determined by a universal material testing machine (Instron 3300; Instron Corporation, Norwood, MA, USA). 
Swelling degree and photothermal conversion properties of hydrogels

The swelling degree of hydrogels was measured based on a gravimetric method. The dehydrated hydrogel samples were immersed in distilled water in the temperature range of $20{ }^{\circ} \mathrm{C}$ to $60{ }^{\circ} \mathrm{C}$. When the samples reached an equilibrium swelling state, the swollen hydrogels were removed from the water, the water was wiped off with filter paper, and the material was immediately weighed. The determination of all samples was conducted in three parallel measurements. The swelling ratio (SR), equilibrium swelling ratio (Seq), and water retention (WR) were calculated as follows (Sun et al. 2013),

$$
\begin{aligned}
& \mathrm{SR}=\left(W_{\mathrm{t}}-W_{\mathrm{o}}\right) / W_{\mathrm{o}} \\
& \mathrm{S}_{\text {eq }}=\left(W_{\mathrm{t}}-W_{\mathrm{o}}\right) / W_{\mathrm{o}} \\
& \mathrm{WR}=\left(W_{\mathrm{t}}-W_{\mathrm{o}}\right) /\left(W_{\text {eq }}-W_{\mathrm{o}}\right)
\end{aligned}
$$

where $W_{\mathrm{t}}$ is the weight $(\mathrm{g})$ of swollen hydrogels, $W_{\mathrm{o}}$ is the weight $(\mathrm{g})$ of dried hydrogels, and $W_{\text {eq }}$ is the equilibrium weight $(\mathrm{g})$ of swollen hydrogels.

The CMX-MNP-PNIPAm/ $\mathrm{Fe}_{3} \mathrm{O}_{4}$ hydrogel $(0.9 \times 0.4 \times 0.3 \mathrm{~cm})$ was placed in a cuvette that contained $0.6 \mathrm{~mL}$ water. The photothermal conversion properties of the hydrogels were measured using near infrared (NIR) irradiation (GKGY-NIR-200; Hengaode Instrument Co., Ltd., Beijing, China), which was performed at $808 \mathrm{~nm}$ with a radiant power of $2 \mathrm{~W}$. The reversibility of photothermal changes was investigated by the swelling-deswelling of the CMX-MNP-PNIPAm/ $/ \mathrm{Fe}_{3} \mathrm{O}_{4}$ hydrogels.

\section{RESULTS AND DISCUSSION}

\section{${ }^{13} \mathrm{C}$-NMR Spectra of Native Xylan, CMX, and Hydrogel}

Figure 1 shows the ${ }^{13} \mathrm{C}-\mathrm{NMR}$ spectra of CMX (a), CMX-MNP-PNIPAm hydrogels (b), and native xylan (c). As shown in Fig. 1a, these peaks at 101.77, 76.48, 73.79, 72.81, and 63.09 ppm are assigned to C-1, C-4, C-3, C-2, and C-5 of the $\beta$-D-xylpyranosyl units of xylan, respectively (Peng et al. 2011a). Compared with the spectrum of xylan (Fig. 1c), two new signals at $68.6 \mathrm{ppm}$ and $178.34 \mathrm{ppm}$ were observed, which were attributed to the $-\mathrm{CH}_{2}$ of the carboxymethyl and carboxyl groups, respectively (Lazik et al. 2002). These results demonstrated that the carboxymethylation occurred on xylan.
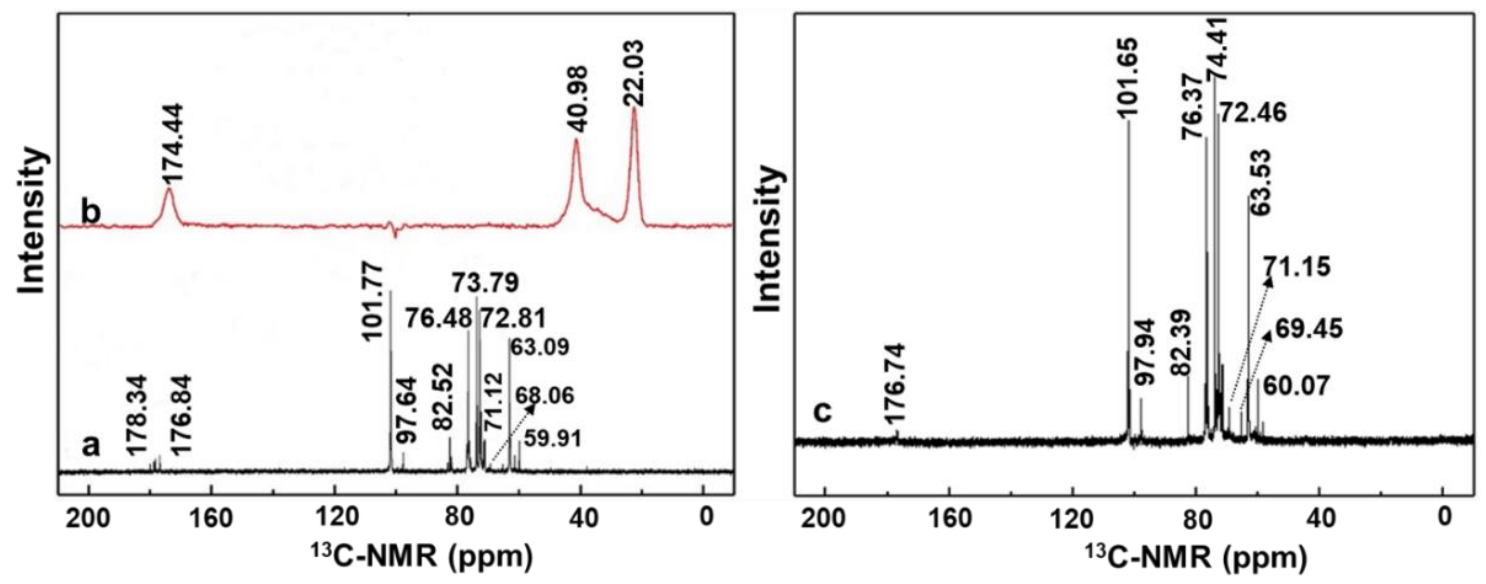

Fig. 1. The ${ }^{13} \mathrm{C}-\mathrm{NMR}$ spectra of CMX (a), CMX-MNP-PNIPAm hydrogels (b), and native xylan (c) 
In Fig 1a, signals at $176.84,97.64,82.52$, and $59.91 \mathrm{ppm}$ are the characteristic signals of C-6, C-1, C-4, and the methoxyl group of the 4- $O$-methyl-D-glucosyluronic acid residue, respectively (Sun et al. 1998). In Fig. 1b, the signals at 22.03 and 40.98 ppm are attributed to the methyl carbon of $\mathrm{N}$-isopropyl (NIPAm) and the vibration of the -CH group (Lo et al. 2005). The peak at 174.44 ppm (Fig. 1b) was ascribed to the carbonyl group $(\mathrm{C}=\mathrm{O})$, which was associated with acrylamide and NIPAm in hydrogels (Lazik et al. 2002). Compared with the spectrum of CMX in Fig. 1a, the characteristic signals of CMX did not appear in Fig. 1b. These changes confirmed that prepared hydrogels did not contain CMX. It was also shown that CMX was eluted as a pore-forming agent during the procedure of synthetic hydrogels.

\section{Morphology Analysis of Hydrogels}

For Fig. 2a through $2 \mathrm{~d}$, it is clearly apparent that hydrogels with pore sizes of $2 \mu \mathrm{m}$ to $10 \mu \mathrm{m}$ were successfully prepared by changing the crosslinking agent amount. With an increase in the amount of MBA, the pore sizes of hydrogels decreased due to improving the crosslinking density. The porous structure of hydrogels became more uniform. This illustrated that the pore sizes of hydrogels could be controlled by adjusting the MBA amount. Figure $2 \mathrm{e}$ and $2 \mathrm{f}$ show the deswelling SEM images of $\mathrm{MBA}_{0.1}$ hydrogels. After deswelling, the network structure of hydrogels shrunk, and then the surface of the hydrogels wrinkled. After magnification (Fig. 2f), the hydrogels surface was a threedimensional porous structure consisting of very small holes. Figures $2 \mathrm{a}$ and $2 \mathrm{~g}$ show the surface appearance of the traditional PNIPAm hydrogels without CMX and CMX-MNPPNIPAm hydrogels (with CMX), respectively. Compared with Fig. 2g, the image in Fig. 2a exhibits a lager pore size and a more stereoscopic network structure at the same preparation conditions. This results indicates that CMX acts as a pore-forming agent in the preparation of the hydrogel and promotes the formation of pore.

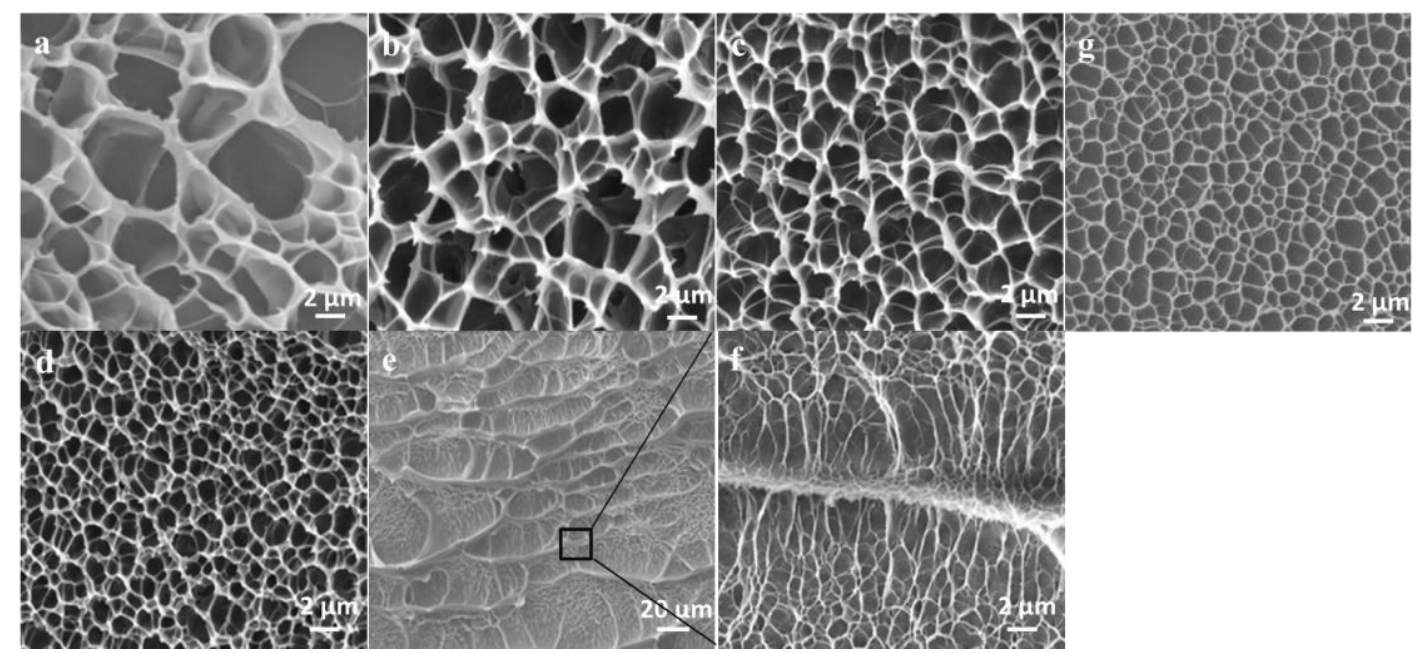

Fig. 2. The SEM images of CMX-MNP-PNIPAm hydrogels: (a) MBA $A_{0.05}$; (b) $M B A_{0.1}$; (c) $M B A_{0.15}$; (d) $\mathrm{MBA}_{0.2} ;(\mathrm{e})$ deswelling $\mathrm{MBA}_{0.1}$; (f) the magnification of deswelling $\mathrm{MBA}_{0.1}$ and $(\mathrm{g})$ traditional PNIPAm hydrogels without CMX

Photographs of CMX-MNP-PNIPAm hydrogels before the fabrication of $\mathrm{Fe}_{3} \mathrm{O}_{4}$ nanoparticles that were synthesized in different $\mathrm{NaCl}$ concentrations without washing with deionized water to remove unreacted chemicals are shown in Fig. 3. It was obvious that all 
hydrogels were light yellow, which was attributed to the presence of carboxymethyl hemicellulose (Kong et al. 2016). The transparent hydrogels $\left(\mathrm{NaC}_{10}\right)$ were obtained in an aqueous solution without sodium chloride. However, hydrogels synthesized in sodium chloride aqueous solution were semi-transparent $\left(\mathrm{NaCl}_{0.2}\right)$ or even opaque $\left(\mathrm{NaCl}_{0.4}\right.$, $\mathrm{NaCl}_{0.6}$ ), indicating that increased $\mathrm{NaCl}$ concentrations caused increases in the opacity degree of the hydrogels. This was due to the existence of pore-forming agent and the $\mathrm{NaCl}$ solutions. In the synthesis process of hydrogels, the repulsion from the CMX chain was depressed in the $\mathrm{NaCl}$ solutions to facilitate the curliness of the CMX chain, and the poreforming agent worked. Meanwhile, the PNIPAm chains curled and intertwined with each other, finally becoming a nucleus, which was due to the fact that the formed PNIPAm chains could not dissolve extendedly in the $\mathrm{NaCl}$ solutions (Zhang et al. 2003b). The agglomeration of the nucleus led to forming a macroporous structure in hydrogels. Therefore, the phase separation easily occurred when the $\mathrm{NaCl}$ solution concentration exceeded $0.2 \mathrm{~mol} / \mathrm{L}$.

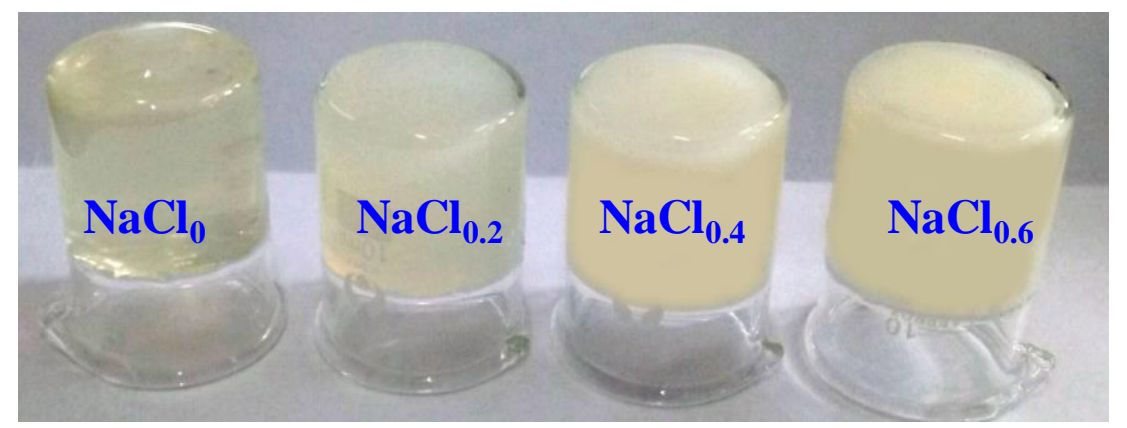

Fig. 3. Digital photograph of CMX-MNP-PNIPAm hydrogels before incorporating $\mathrm{Fe}_{3} \mathrm{O}_{4}$ nanoparticles

\section{Magnetic Particle Analysis in Hydrogels}

As shown in Fig. 4a, CMX-MNP-PNIPAm/ $/ \mathrm{Fe}_{3} \mathrm{O}_{4}$ hydrogels had apparent diffraction peaks at $2 \theta=30.25^{\circ}, 35.70^{\circ}, 43.16^{\circ}, 53.94^{\circ}, 57.42^{\circ}$, and $62.83^{\circ}$, which are ascribed to the (220), (311), (400), (422), (511), and (440) planes of $\mathrm{Fe}_{3} \mathrm{O}_{4}$, respectively (Zhu et al. 2014). The Raman spectrum in Fig. $4 \mathrm{~b}$ shows a single peak at $670 \mathrm{~cm}^{-1}$, which was consistent with the characteristic peak of $\mathrm{Fe}_{3} \mathrm{O}_{4}$ (Shebanova and Lazor 2003), but is different from that of $\mathrm{Fe}_{2} \mathrm{O}_{3}$, which has three prominent peaks around 350, 500, and 700 $\mathrm{cm}^{-1}$ (Wang et al. 2009). Therefore, $\mathrm{Fe}_{3} \mathrm{O}_{4}$ particles were in-situ prepared within the network of CMX-MNP-PNIPAm hydrogels. The hysteresis loop and the SEM image of CMX-MNP-PNIPAm/Fe ${ }_{3} \mathrm{O}_{4}$ hydrogels are shown in Fig. $4 \mathrm{c}$ and $4 \mathrm{~d}$, respectively. Clearly, the saturation magnetization of CMX-MNP-PNIPAm/ $/ \mathrm{Fe}_{3} \mathrm{O}_{4}$ hydrogels was 10.78 to 12.51 $\mathrm{emu} / \mathrm{g}$. This value was increased with the increase of crosslinking concentration, which was due to the influence of the crosslinking concentration on the magnetism of $\mathrm{Fe}_{3} \mathrm{O}_{4}$ by affecting the pore structure of hydrogels (Gao et al. 2014). When the pore size of the hydrogels network was less than $2 \mu \mathrm{m}$, the anisotropy of $\mathrm{Fe}_{3} \mathrm{O}_{4}$ nanoparticles began to grow (Gnanaprakash et al. 2007). Moreover, the hysteresis loop of the prepared hydrogels did not decrease obviously. The hydrogels exhibited apparent superparamagnetism. Therefore, it was demonstrated that the crosslinking concentration of hydrogels had an apparent effect on the $\mathrm{Fe}_{3} \mathrm{O}_{4}$ particles by affecting the pores structures of hydrogels. In Fig. $4 d$, the $\mathrm{Fe}_{3} \mathrm{O}_{4}$ particles were uniformly distributed in the hydrogels' network, and the size was approximately $10 \mathrm{~nm}$. 

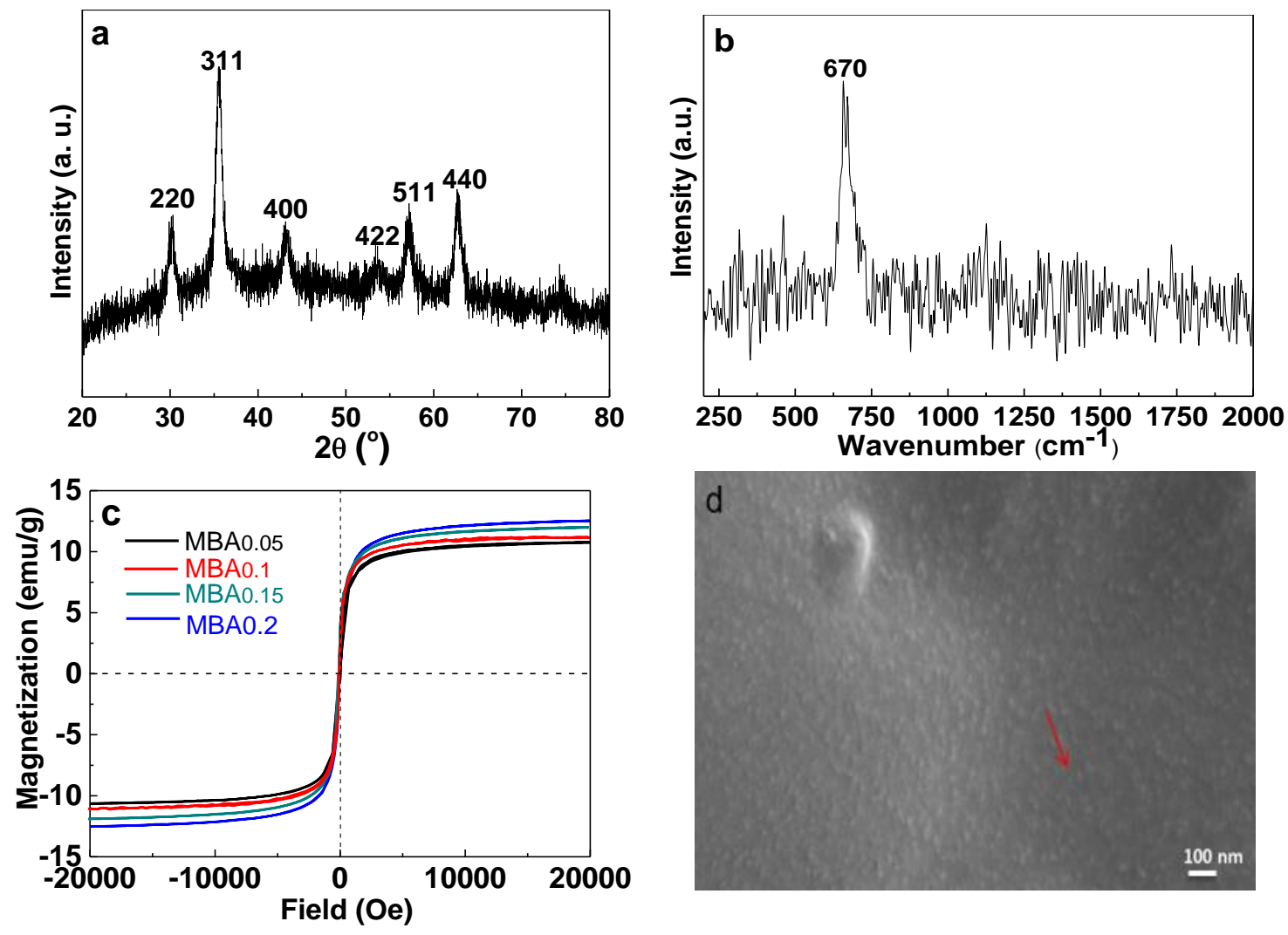

Fig. 4. The XRD spectra (a) and Raman spectra (b) of CMX-MNP-PNIPAm/ $\mathrm{Fe}_{3} \mathrm{O}_{4}\left(\mathrm{MBA}_{0.2}\right)$; hysteresis loop (c) of CMX-MNP-PNIPAm/ $/ \mathrm{Fe}_{3} \mathrm{O}_{4}$ hydrogels with different MBA amounts, and SEM image (d) of CMX-MNP-PNIPAm/ $/ \mathrm{Fe}_{3} \mathrm{O}_{4}$ hydrogels

\section{Thermogravimetric and Mechanical Property Analysis of Hydrogels}

Thermogravimetric analysis of the CMX-MNP-PNIPAm/ $/ \mathrm{Fe}_{3} \mathrm{O}_{4}$ hydrogels is shown in Fig. 5. It was obvious that the weight loss of CMX and hydrogels occurred at approximately $200{ }^{\circ} \mathrm{C}$ to $300{ }^{\circ} \mathrm{C}$ and $300{ }^{\circ} \mathrm{C}$ to $400{ }^{\circ} \mathrm{C}$, respectively. This illustrated that hydrogels did not contain CMX, which was consistent with the analysis of the abovementioned Fig. 1. The weight loss at $200{ }^{\circ} \mathrm{C}$ to $300{ }^{\circ} \mathrm{C}$ was mainly attributed to the degradation of molecular chains of CMX, and the mass loss in the range of $250{ }^{\circ} \mathrm{C}$ to 300 ${ }^{\circ} \mathrm{C}$ was ascribed to the dehydroxylation and decarboxylation of xylan (Peng et al. 2015). The weight loss at $300{ }^{\circ} \mathrm{C}$ to $400{ }^{\circ} \mathrm{C}$ was ascribed to the cleavage of the carbon backbone in hydrogels (Ghorpade et al. 2018). When the temperature was above $400^{\circ} \mathrm{C}$, the weight of the sample related to carbonization gradually decreased and leveled off. Similar TG curves were observed for CMX-MNP-PNIPAm/ $/ \mathrm{Fe}_{3} \mathrm{O}_{4}$ hydrogels with different MBA amounts, which demonstrated that MBA had no effect on the thermal stability of hydrogels. These changes showed that $\mathrm{CMX}-\mathrm{MNP}-\mathrm{PNIPAm} / \mathrm{Fe}_{3} \mathrm{O}_{4}$ hydrogels had a good thermal stability compared to CMX.

In addition to thermal stability of hydrogels, strength is also an important criterion. Figure 6 displays the compressive stress-strain curve of CMX-MNP-PNIPAm/ $/ \mathrm{Fe}_{3} \mathrm{O}_{4}$ hydrogels. Clearly, the compressive stress of hydrogels increased with the amount of MBA crosslinking agent. When the amount of MBA was the maximum, the compressive stress of the $\mathrm{MBA}_{0.2}$ sample could reach $180 \mathrm{kPa}$, and the corresponding compressive strain reached $66 \%$. One possible explanation was that $\mathrm{Fe}_{3} \mathrm{O}_{4}$ nanoparticles were fabricated in the 
hydrogel network by co-precipitation and dispersed more evenly in the hydrogels, resulting in improved compression strength (Dai et al. 2016). For Fig. 6b, the CMX-MNP$\mathrm{PNIPAm} / \mathrm{Fe}_{3} \mathrm{O}_{4}$-hydrogels had good compression properties.

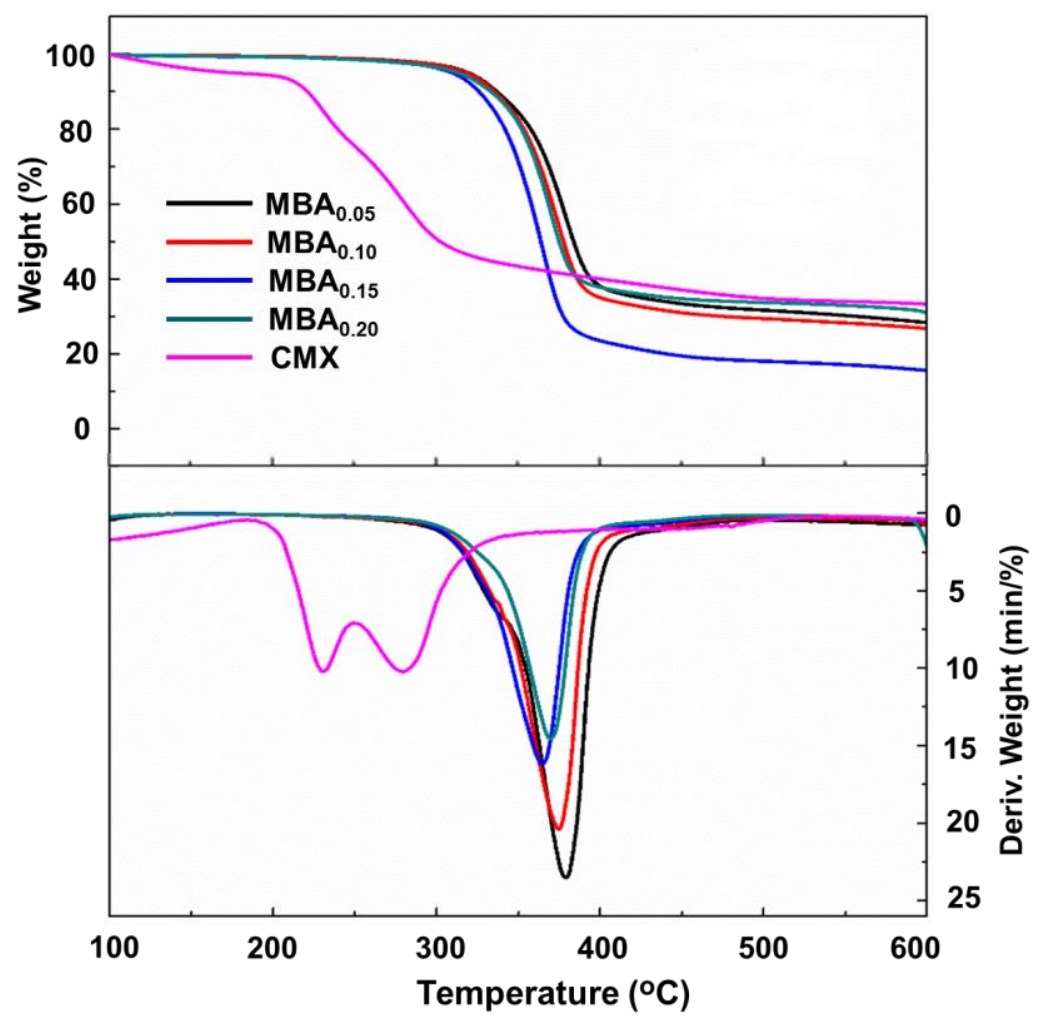

Fig. 5. TG curves of CMX-MNP-PNIPAm/ $/ \mathrm{Fe}_{3} \mathrm{O}_{4}$ hydrogels and $\mathrm{CMX}$
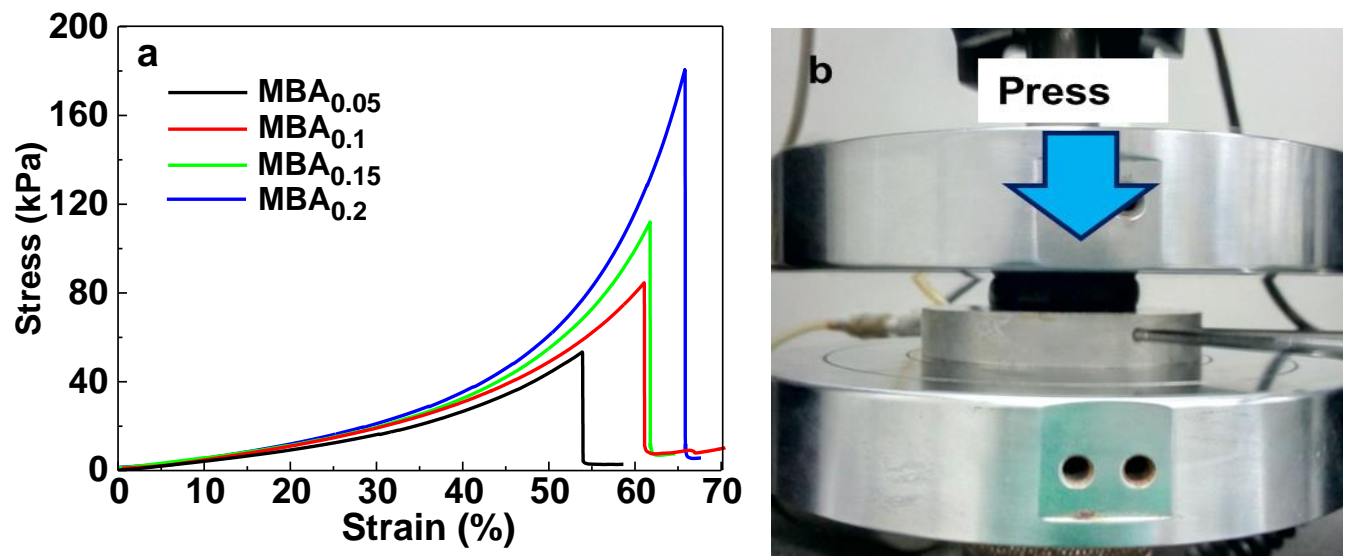

Fig. 6. The compressive strength of the CMX-MNP-PNIPAm/ $/ \mathrm{Fe}_{3} \mathrm{O}_{4}$ hydrogels (a) and the compressive test of CMX-MNP-PNIPAm/Fe $3 \mathrm{O}_{4}$ hydrogels $\left(\mathrm{MBA}_{0.2}\right)(\mathrm{b})$

\section{Deswelling Behavior of Hydrogels}

The SR of CMX-MNP-PNIPAm/ $/ \mathrm{Fe}_{3} \mathrm{O}_{4}$ hydrogels with different MBA amounts as a function of different temperatures is shown in Fig. 7a. The SR of all hydrogels decreased with an increase in the temperature in $60 \mathrm{~min}$. Especially, when the temperature from 36 
${ }^{\circ} \mathrm{C}$ rose to $38^{\circ} \mathrm{C}$, the SR of hydrogels decreased sharply at different MBA amounts. This illustrated that the volume of hydrogels shrank rapidly when the temperature exceeded 38 ${ }^{\circ} \mathrm{C}$. Figure $7 \mathrm{~b}$ shows the DSC curves of the CMX-MNP-PNIPAm/ $/ \mathrm{Fe}_{3} \mathrm{O}_{4}$ hydrogels with different AM amounts. The DSC curves of prepared hydrogels showed a rising trend with an increase of the temperature from $5^{\circ} \mathrm{C}$ to $60{ }^{\circ} \mathrm{C}$, which was attributed to the production of evaporation of enthalpy in the hydrogels when the temperature increased (Hou et al. 2008). All of the hydrogels showed an obvious peak near $36{ }^{\circ} \mathrm{C}$ to $38{ }^{\circ} \mathrm{C}$, which was due to the production of the phase transition enthalpy caused by the phase transition of hydrogels. The corresponding temperature of the peak was the LCST of hydrogels (Ma et al. 2012), and the LCST gradually rose following the increase in the AM amount. The LCST of CMX-MNP-PNIPAm/ $\mathrm{Fe}_{3} \mathrm{O}_{4}$ hydrogels were $35.83{ }^{\circ} \mathrm{C}, 36.70{ }^{\circ} \mathrm{C}, 37.84{ }^{\circ} \mathrm{C}$, and $38.60{ }^{\circ} \mathrm{C}$, corresponding to 0.05-M, 0.1-M, 0.2-M, and 0.4-M AM, respectively. Clearly, the LCST of CMX-MNP-PNIPAm/ $/ \mathrm{Fe}_{3} \mathrm{O}_{4}$ hydrogels could be controlled by adjusting the AM amounts. This was because hydrophilic acrylamide was introduced into the hydrogels network, increasing the hydrophilic group ratio of the hydrogels network, further forming more hydrogen bonds, and requiring more energy to break the hydrogen bonds (Wang et al. 2013). At near $0{ }^{\circ} \mathrm{C}$, the hydrogel had a remarkable endothermic peak corresponding to the phase transition of free water (Tamai et al. 1996), indicating that there was a glass transition between $-10{ }^{\circ} \mathrm{C}$ to $0{ }^{\circ} \mathrm{C}$ after the swelling of hydrogels in distilled water.
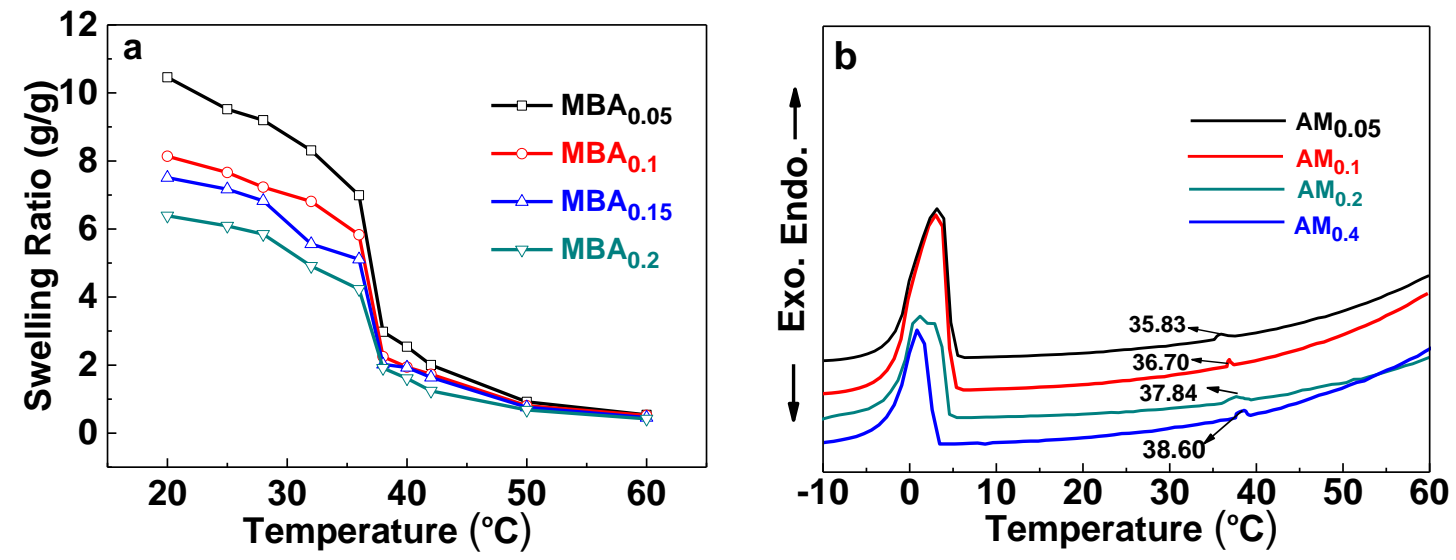

Fig. 7. The equilibrium swelling ratio (a) and the DSC curves (b) of CMX-MNP-PNIPAm/ $/ \mathrm{e}_{3} \mathrm{O}_{4}$ hydrogels with different MBA amounts

The swelling behavior of CMX-MNP-PNIPAm/ $/ \mathrm{Fe}_{3} \mathrm{O}_{4}$ hydrogels at $20{ }^{\circ} \mathrm{C}$ and deswelling behavior at $60{ }^{\circ} \mathrm{C}$ were studied. The effect of MBA amounts on the equilibrium swelling rate of hydrogels is shown in Fig. 8a. The equilibrium swelling rates of hydrogels first increased and then leveled off with the increase of time and decreased with the increase of MBA amounts at $20^{\circ} \mathrm{C}$. When MBA was $0.05 \mathrm{~g}, 0.1 \mathrm{~g}, 0.15 \mathrm{~g}$, and $0.2 \mathrm{~g}$, the equilibrium swelling rate of CMX-MNP-PNIPAm/ $\mathrm{Fe}_{3} \mathrm{O}_{4}$ hydrogels was $10.47 \mathrm{~g} / \mathrm{g}, 8.12 \mathrm{~g} / \mathrm{g}, 7.52 \mathrm{~g} / \mathrm{g}$, and $6.44 \mathrm{~g} / \mathrm{g}$, respectively, indicating that the crosslinking agent had a positive influence on the crosslinking density and accordingly had an impact on the SR of hydrogels. The deswelling behavior of the CMX-MNP-PNIPAm/ $/ \mathrm{Fe}_{3} \mathrm{O}_{4}$ hydrogels was shown in different $\mathrm{NaCl}$ concentrations at $60{ }^{\circ} \mathrm{C}$ (Fig. 8b). With the increase of $\mathrm{NaCl}$ concentration, the capacity of hydrogels to hold water clearly decreased. When the concentration of $\mathrm{NaCl}$ was above $0.2 \mathrm{M}$, the water retention rate of hydrogels was less than $15 \%$ in $1 \mathrm{~min}$. In addition, the water retention rate of hydrogels prepared without $\mathrm{NaCl}$ was clearly higher than that of 
the samples prepared in the $\mathrm{NaCl}$ solution. This change illustrated that the $\mathrm{NaCl}$ had a positive effect on the deswelling behavior of the hydrogels. In the $\mathrm{NaCl}$ medium, the repulsion from the CMX chain was depressed by the shielding effect of the small molecular electrolytes to facilitate the curliness of the CMX chain (Annaka et al. 2000). Additionally, the monomers and crosslinking agents were clustered around carboxymethyl xylan to form a macroporous structure in hydrogels. After the removal of CMX, the heterogeneous porous hydrogels were obtained, which demonstrated that the CMX played a key role as the pore-forming agent in the preparation of hydrogels in $\mathrm{NaCl}$ solutions (Cheng et al. 2003).

The deswelling behavior of hydrogels at different AM amounts is shown in Fig. 8c. The water retention rate of hydrogels increased with the increase of AM amounts. When the AM amount was $0.05 \mathrm{M}$, the water retention rate of the hydrogels was less than $15 \%$ in $50 \mathrm{~s}$. This was because water molecules in hydrogels were blocked and difficult to spread due to forming more hydrogen bonds by introducing more hydrophilic AM into the hydrogels network. This trend was consistent with the conclusion obtained from a previous study that the water retention of hydrogels increased with the increase of AM in $6000 \mathrm{~s}$ (Gao et al. 2015).
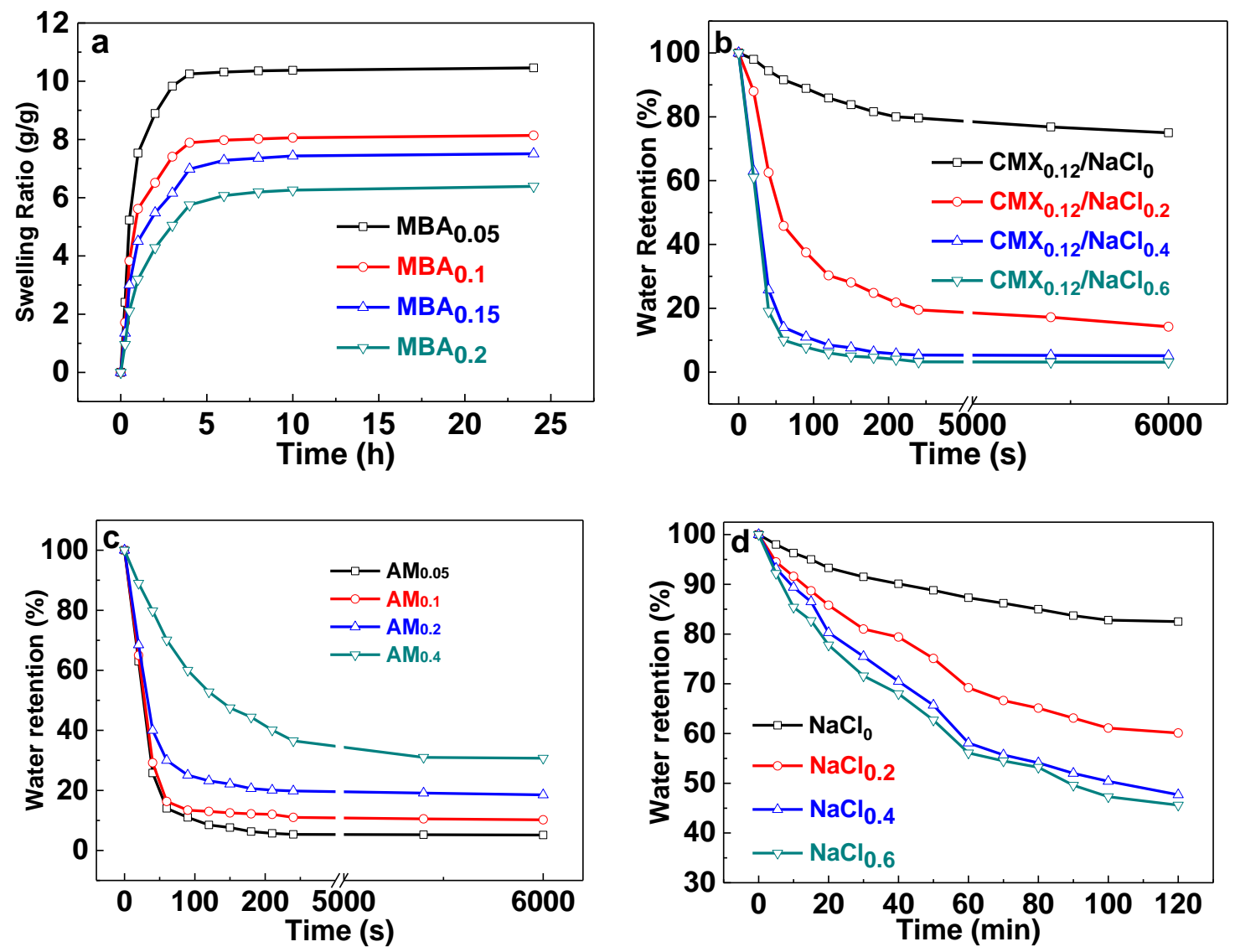

Fig. 8. The swelling behavior and deswelling behavior of $\mathrm{CMX}-\mathrm{MNP}-\mathrm{PNIPAm} / \mathrm{Fe}_{3} \mathrm{O}_{4}$ hydrogels: (a) different MBA amounts at $20^{\circ} \mathrm{C}$; (b) different $\mathrm{NaCl}$ concentrations at $60^{\circ} \mathrm{C}$; (c) different $\mathrm{AM}$ amounts at $60^{\circ} \mathrm{C}$; and (d) the influence of different $\mathrm{NaCl}$ concentrations on deswelling behavior of the hydrogel at $60^{\circ} \mathrm{C}$ without $\mathrm{CMX}$ 
Figure 8d depicts the deswelling of hydrogels in different concentrations of $\mathrm{NaCl}$ solutions in the absence of CMX. Clearly, hydrogels prepared in the absence of $\mathrm{NaCl}$ and CMX showed a slow deswelling rate and a high water retention rate of $85 \%$ in $120 \mathrm{~min}$. However, the deswelling rate of prepared hydrogels increased with the concentration of $\mathrm{NaCl}$ in the absence of CMX. The deswelling rate of hydrogels prepared with the addition of $\mathrm{CMX}$ and $\mathrm{NaCl}$ solutions were remarkably faster than that of hydrogels without $\mathrm{CMX}$. For example, the hydrogel prepared with $\mathrm{CMX}$ in $0.6 \mathrm{M} \mathrm{NaCl}$ solution lost at least $85 \%$ water within $20 \mathrm{~s}$, whereas the hydrogel without CMX lost only approximately $15 \%$ in 120 min. This improved property demonstrated that the CMX played an important role in the process of preparing hydrogels in $\mathrm{NaCl}$ solutions. The shielding effect of the $\mathrm{NaCl}$ small molecule made the molecular chain of CMX curl into particles that were easily removed during the washing of hydrogels. Thus, CMX acted as the pore-forming agent during the hydrogels preparation (Wu et al. 1992).

\section{Photothermal Properties of Hydrogels}

The photothermal properties of CMX-MNP-PNIPAm/ $/ \mathrm{Fe}_{3} \mathrm{O}_{4}$ hydrogels were investigated in Fig. 9. In Fig. 9a, a small piece of CMX-MNP-PNIPAm/ $\mathrm{Fe}_{3} \mathrm{O}_{4}$ hydrogels was placed in a quartz-type cell that contained $0.6 \mathrm{~mL}$ of water. Then, they were exposed to the NIR laser of $808 \mathrm{~nm}(2 \mathrm{~W})$ for $2 \mathrm{~min}$. The volume phase transition of hydrogels was observed under a laser irradiation in $2 \mathrm{~min}$, which was due to the temperature of hydrogels being above its LCST under the photothermal effect induced by black $\mathrm{Fe}_{3} \mathrm{O}_{4}$ particles in the hydrogels (Zhu et al. 2014).
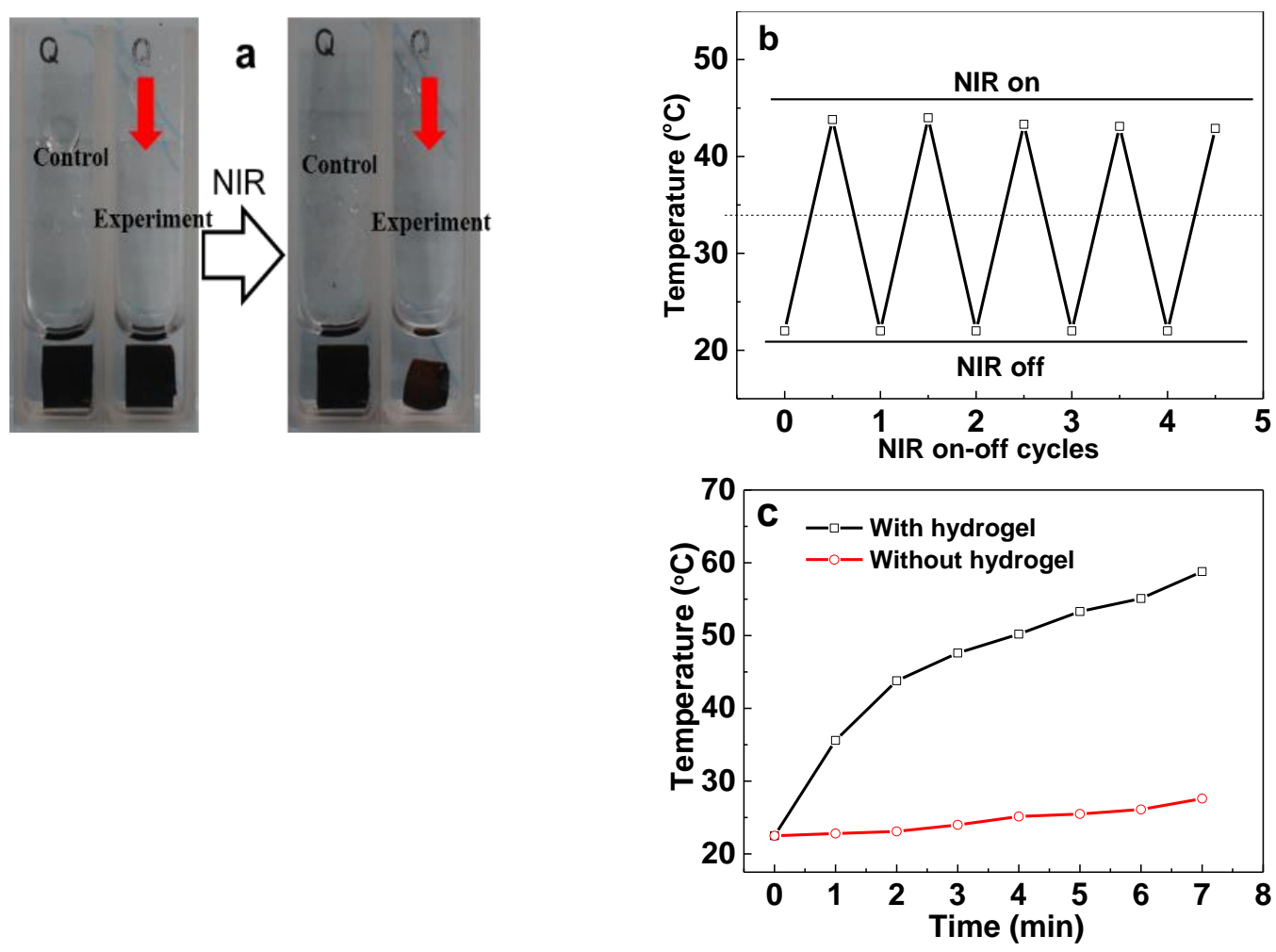

Fig. 9. The volume phase transition of hydrogels (CMX/MBA/AM/NaCl in Table 1) under the NIR irradiation (a); the change of the water temperature under the NIR on-off cycles (b); and change of water temperature under the NIR irradiation (c) $(808 \mathrm{~nm}, 2 \mathrm{~W})$ 
After removing the laser, hydrogels recovered from a shrunken state to a swollen state like the original one, suggesting that the photothermal reversibility of hydrogels was excellent. To further confirm the photothermal reversibility of the hydrogel, the NIR irradiation experiment was repeated several times, and the results are shown in Fig. 9b. When the laser was removed after 2 min of irradiation, the temperature of the water was immediately measured with a probe. Hydrogels could be controlled to be shrunken/swollen by adjusting the NIR laser on/off, and the water temperature followed the change, suggesting that the phase transitions of the hydrogels were completely reversible. In Fig. $9 \mathrm{c}$, the water temperature of CMX-MNP-PNIPAm/ $/ \mathrm{Fe}_{3} \mathrm{O}_{4}$ hydrogels increased with the increase of irradiation time. The NIR-induced temperature increased to $59{ }^{\circ} \mathrm{C}$ in $7 \mathrm{~min}$, whereas no obvious temperature variation was observed without the hydrogel at the same laser irradiation. These changes demonstrated that the prepared CMX-MNPPNIPAm $/ \mathrm{Fe}_{3} \mathrm{O}_{4}$ hydrogels could absorb and transform NIR laser into heat, and the volume phase transition under NIR irradiation was reversible. More importantly, the in-situ formation of $\mathrm{Fe}_{3} \mathrm{O}_{4}$ nanoparticles during the preparation of hydrogels not only endows the hydrogels with photothermal properties, but also endows them with magnetism, which is conducive to their further utilization and recovery.

\section{CONCLUSIONS}

1. Temperature fast-responsive, magnetic carboxymethylxylan-magnetic nanoparticle$\operatorname{poly}\left(N\right.$-isopropylacrylamide) $-\mathrm{Fe}_{3} \mathrm{O}_{4} \quad\left(\mathrm{CMX}-\mathrm{MNP}-\mathrm{PNIPAm} / \mathrm{Fe}_{3} \mathrm{O}_{4}\right)$ hydrogels were successfully prepared using carboxymethyl xylan as the pore-forming agent in the $\mathrm{NaCl}$ solution. The obtained hydrogels exhibited a fast, temperature-responsive behavior and the water retention was less than $15 \%$ for 1 min under $60{ }^{\circ} \mathrm{C}$.

2. The CMX played an important role in pore-making at the process of preparing hydrogels. The CMX-MNP-PNIPAm hydrogels with CMX showed intensive aperture networks structure and larger pore size compared with the hydrogels without CMX.

3. The lower critical solution temperature (LCST) of the CMX-MNP-PNIPAm/ $\mathrm{Fe}_{3} \mathrm{O}_{4}$ hydrogels could be controlled by adjusting the hydrophilic monomer (AM) amounts. Hydrogels also showed good photothermal transformation performance and had great compression properties. The hydrogels could be heated to $40{ }^{\circ} \mathrm{C}$ within $2 \mathrm{~min}$, and to $69{ }^{\circ} \mathrm{C}$ within 7 min under near infrared irradiation.

\section{ACKNOWLEDGMENTS}

This work was financially supported the National Natural Science Foundation of China (No. 201406080), the Science and Technology Planning Project of Guangdong Province, China (No. 2017A010103032), and the Guangdong Program for Support of Topnotch Young Professionals (No. 2016TQ03Z585). 


\section{REFERENCES CITED}

Annaka, M., Motokawa, K., Sasaki, S., Nakahira, T., Kawasaki, H., Maeda, H., Amo, Y., and Tominaga, Y. (2000). "Salt-induced volume phase transition of poly(Nisopropylacrylamide) gel," J. Chem. Phys. 113(14), 5980-5985. DOI: 10.1063/1.1290135

Ashraf, S., Park, H.-K., Park, H., and Lee, S.-H. (2016). "Snapshot of phase transition in thermoresponsive hydrogel PNIPAM: Role in drug delivery and tissue engineering," Macromol. Res. 24(4), 297-304. DOI: 10.1007/s13233-016-4052-2

Cheng, S.-X., Zhang, J.-T., and Zhuo, R.-X. (2003). "Macroporous poly(Nisopropylacrylamide) hydrogels with fast response rates and improved protein release properties," J. Biomed. Mater. Res. A 67(1), 96-103. DOI: 10.1002/jbm.a.10062

Dai, Q.-Q., Ren, J.-L., Peng, F., Chen, X.-F., Gao, C.-D., and Sun, R.-C. (2016). "Synthesis of acylated xylan-based magnetic $\mathrm{Fe}_{3} \mathrm{O}_{4}$ hydrogels and their application for $\mathrm{H}_{2} \mathrm{O}_{2}$ detection," Materials 9(8), 690. DOI: 10.3390/ma9080690

Ebringerová, A., and Heinze, T. (2000). "Xylan and xylan derivatives - biopolymers with valuable properties, 1. Naturally occurring xylans structures, isolation procedures and properties," Macromol. Rapid Comm. 21(9), 542-556. DOI: 10.1002/15213927(20000601)21:9<542::AID-MARC542>3.0.CO;2-7

Gao, C. D., Ren, J. L., Kong, W. Q., Sun, R. C., and Chen, Q. F. (2015). “Comparative study on temperature/pH sensitive xylan-based hydrogels: Their properties and drug controlled release," RSC Adv. 5(110), 90671-90681. DOI: 10.1039/C5RA16703E

Gao, Y., Wei, Z., Li, F., Yang, Z. M., Chen, Y. M., Zrinyi, M., and Osada, Y. (2014). "Synthesis of a morphology controllable $\mathrm{Fe}_{3} \mathrm{O}_{4}$ nanoparticle/hydrogel magnetic nanocomposite inspired by magnetotactic bacteria and its application in $\mathrm{H}_{2} \mathrm{O}_{2}$ detection," Green Chem. 16(3), 1255-1261. DOI: 10.1039/C3GC41535J

Ghorpade, V. S., Yadav, A. V., Dias, R. J., Mali, K. K., Pargaonkar, S. S., Shinde, P. V., and Dhane, N. S. (2018). "Citric acid crosslinked carboxymethylcellulosepoly(ethylene glycol) hydrogel films for delivery of poorly soluble drugs," Int. J. Biol. Macromol. 118(15), 783-791. DOI: 10.1016/j.ijbiomac.2018.06.142

Gnanaprakash, G., Mahadevan, S., Jayakumar, T., Kalyanasundaram, P., Philip, J., and Raj, B. (2007). "Effect of initial $\mathrm{pH}$ and temperature of iron salt solutions on formation of magnetite nanoparticles," Mater. Chem. Phys. 103(1), 168-175. DOI: 10.1016/j.matchemphys.2007.02.011

Higgins, W., Kozlovskaya, V., Alford, A., Ankner, J., and Kharlampieva, E. (2016). "Stratified temperature-responsive multilayer hydrogels of poly(N-vinylpyrrolidone) and poly(N-vinylcaprolactam): Effect of hydrogel architecture on properties," Macromolecules 49(18), 6953-6964. DOI: 10.1021/acs.macromol.6b00964

Hou, Y. P., Matthews, A. R., Smitherman, A. M., Bulick, A. S., Hahn, M. S., Hou, H. J., Han, A., and Grunlan, M. A. (2008). "Thermoresponsive nanocomposite hydrogels with cell-releasing behavior," Biomaterials 29(22), 3175-3184. DOI: 10.1016/j.biomaterials.2008.04.024

Kong, W. Q., Huang, D. Y., Xu, G. B., Ren, J. L., Liu, C. F., Zhao, L. Y., and Sun, R. C. (2016). "Graphene oxide/polyacrylamide/aluminum ion cross-linked carboxymethyl hemicellulose nanocomposite hydrogels with very tough and elastic properties," Chem.-Asian J. 11(11), 1697-1704. DOI: 10.1002/asia.201600138 
Lazik, W., Heinze, T., Pfeiffer, K., Albrecht, G., and Mischnick, P. (2002). "Starch derivatives of a high degree of functionalization. VI. Multistep carboxymethylation," J. Appl. Polym. Sci. 86(3), 743-752. DOI: 10.1002/app.10983

Lo, C.-L., Lin, K.-M., and Hsiue, G.-H. (2005). "Preparation and characterization of intelligent core-shell nanoparticles based on poly(d,l-lactide)-g-poly( $\mathrm{N}$-isopropyl acrylamide-co-methacrylic acid)," J. Control. Release 104(3), 477-488. DOI: 10.1016/j.jconrel.2005.03.004

Ma, Y.-X., Li, Y.-F., Zhao, G.-H., Yang, L.-Q., Wang, J.-Z., Shan, X., and Yan, X. (2012). "Preparation and characterization of graphite nanosheets decorated with $\mathrm{Fe}_{3} \mathrm{O}_{4}$ nanoparticles used in the immobilization of glucoamylase," Carbon 50(8), 2976-2986. DOI: 10.1016/j.carbon.2012.02.080

Peng, X.-W., Ren, J.-L., Zhong, L.-X., Cao, X.-F., and Sun, R.-C. (2011a). "Microwaveinduced synthesis of carboxymethyl hemicelluloses and their rheological properties," J. Agr. Food Chem. 59(2), 570-576. DOI: 10.1021/jf1036239

Peng, X.-W., Ren, J.-L., Zhong, L.-X., Peng, F., and Sun, R.-C. (2011b). "Xylan-rich hemicelluloses-graft-acrylic acid ionic hydrogels with rapid responses to $\mathrm{pH}$, salt, and organic solvents," J. Agr. Food Chem. 59(15), 8208-8215. DOI: 10.1021/jf201589y

Peng, X.-W., Zhong, L.-X., Ren, J.-L., and Sun, R.-C. (2012). "Highly effective adsorption of heavy metal ions from aqueous solutions by macroporous xylan-rich hemicelluloses-based hydrogel," J. Agr. Food Chem. 60(15), 3909-3916. DOI: $10.1021 / \mathrm{jf} 300387 \mathrm{q}$

Peng, P., Zhai, M. Z., She, D., and Gao, Y. F. (2015). "Synthesis and characterization of carboxymethyl xylan-g-poly(propylene oxide) and its application in films," Carbohyd. Polym. 133(20), 117-125. DOI:10.1016/j.carbpol.2015.07.009

Ren, J.-L., Sun, R.-C., and Peng, F. (2008). "Carboxymethylation of hemicelluloses isolated from sugarcane bagasse," Polym. Degrad. Stabil. 93(4), 786-793. DOI: 10.1016/j.polymdegradstab.2008.01.011

Shebanova, O. N., and Lazor, P. (2003). "Raman study of magnetite $\left(\mathrm{Fe}_{3} \mathrm{O}_{4}\right)$ : Laserinduced thermal effects and oxidation," J. Raman Spectrosc. 34(11), 845-852. DOI: 10.1002/jrs. 1056

Shekhar, S., Mukherjee, M., and Sen, A. K. (2016). "Swelling, thermal and mechanical properties of NIPAM-based terpolymeric hydrogel," Polym. Bull. 73(1), 125-145. DOI: $10.1007 / \mathrm{s} 00289-015-1476-3$

Shibayama, M., and Nagai, K. (1999). "Shrinking kinetics of poly(Nisopropylacrylamide) gels T-jumped across their volume phase transition temperatures," Macromolecules 32(22), 7461-7468. DOI: 10.1021/ma990719v

Sun, R. C., Mott, L., and Bolton, J. (1998). "Isolation and fractional characterization of ball-milled and enzyme lignins from oil palm trunk," J. Agr. Food Chem. 46(2), 718723. DOI: $10.1021 /$ jf9705532

Sun, X.-F., Wang, H.-H., Jing, Z.-X., and Mohanathas, R. (2013). "Hemicellulose-based pH-sensitive and biodegradable hydrogel for controlled drug delivery," Carbohyd. Polym. 92(2), 1357-1366. DOI: 10.1016/j.carbpol.2012.10.032

Tamai, Y., Tanaka, H., and Nakanishi, K. (1996). "Molecular dynamics study of polymer-water interaction in hydrogels. 2. Hydrogen-bond dynamics," Macromolecules 29(21), 6761-6769. DOI: 10.1021/ma960961r

Wang, S. Y., Li, H. L., Ren, J. L., Liu, C. F., Peng, F., and Sun, R. C. (2013). "Preparation of xylan citrate-A potential adsorbent for industrial wastewater treatment," Carbohyd. Polym. 92(2), 1960-1965. DOI: 10.1016/j.carbpol.2012.11.079 
Wang, Y. L., Li, B. Q., Zhou, Y., and Jia, D. C. (2009). "In situ mineralization of magnetite nanoparticles in chitosan hydrogel," Nanoscale Res. Lett. 4(9), 1041-1046. DOI: $10.1007 / \mathrm{s} 11671-009-9355-1$

Wu, X. S., Hoffman, A. S., and Yager, P. (1992). "Synthesis and characterization of thermally reversible macroporous poly(N-isopropylacrylamide) hydrogels," J. Polym. Sci. Al 30(10), 2121-2129. DOI: 10.1002/pola.1992.080301005

Zhang, J.-T., Cheng, S.-X., Huang, S.-W., and Zhuo, R.-X. (2003a). "Temperaturesensitive poly(N-isopropylacrylamide) hydrogels with macroporous structure and fast response rate," Macromol. Rapid Comm. 24(7), 447-451. DOI: 10.1002/marc.200390061

Zhang, J. T., Cheng, S. X., and Zhuo, R. X. (2003b). "Preparation of macroporous poly(N-isopropylacrylamide) hydrogel with improved temperature sensitivity," $J$. Polym. Sci. Al 41(15), 2390-2392. DOI: 10.1002/pola.10785

Zhang, X.-Z., and Zhuo, R.-X. (2000). "Preparation of fast responsive, thermally sensitive poly(N-isopropylacrylamide) gel," Eur. Polym. J. 36(10), 2301-2303. DOI: 10.1016/S0014-3057(99)00297-9

Zhu, C.-H., Lu, Y., Chen, J.-F., and Yu, S.-H. (2014). "Photothermal poly(Nisopropylacrylamide)/ $/ \mathrm{Fe}_{3} \mathrm{O}_{4}$ nanocomposite hydrogel as a movable position heating source under remote control," Small 10(14), 2796-2800. DOI: 10.1002/smll.201400477

Article submitted: May 30, 2019; Peer review completed: August 25, 2019; Revised version received and accepted: September 6, 2019; Published: September 12, 2019. DOI: $10.15376 /$ biores. 14.4.8543-8558 